\section{Commentary: The secret life of aortic dissections}

\author{
Grayson H. Wheatley III, MD
}

Positive remodeling of the thoracoabdominal aorta in patients with type B aortic dissection (TBAD) is a complex and incompletely understood process. Positive remodeling of the aorta after thoracic endovascular aortic repair (TEVAR) refers to (1) an increase in true-lumen diameter, (2) a progressive thrombosis of the false lumen, and (3) a subsequent reduction in maximal aortic diameter with time. It is our understanding that positive aortic remodeling after TEVAR for TBAD contributes to a long-term, durable aortic repair and freedom from aortic-related mortality. ${ }^{1}$ Numerous anatomic and clinical variables have been identified that can influence the degree of positive aortic remodeling achieved in patients with acute and chronic TBAD. ${ }^{2}$

In this issue of the Journal, $\mathrm{Li}$ and colleagues ${ }^{3}$ introduce us to a straightforward, yet novel, radiographic index that takes into account the combined tortuosity of the aortic arch and the descending thoracic aorta. They then expertly demonstrate how this aortic tortuosity index affects the occurrence of positive aortic remodeling after TEVAR in patients with acute TBAD. It is well appreciated that patients with TBAD possess significant tortuosity of the aorta, as evidenced by imaging such as computed tomographic angiography. Previous attempts to characterize aortic tortuosity were focused on isolated segments of the aorta, such as the aortic arch or the descending thoracic aorta. $\mathrm{Li}$ and colleagues ${ }^{3}$ have taken a step back and developed an index that takes into account comprehensive aorta tortuosity (aortic arch and descending thoracic aorta) and insightfully draws parallels between aortic configuration and the geometry of a question mark.

The degree of aortic angulation in this study was determined by calculating the angle $(\Phi)$ created by the line formed between the apex of the aortic arch (y-axis) and the lateral most point of curvature of the descending

From the Wheatley Medical Group, Nashville, Tenn.

Disclosures: Dr Wheatley serves as a consultant for Medtronic, Terumo Aortic, and Ethicon.

Received for publication July 21, 2019; accepted for publication July 22, 2019; available ahead of print Aug 22, 2019.

Address for reprints: Grayson H. Wheatley III, MD, 1212 Laurel St, Suite 702, Nashville, TN 37203 (E-mail: ghw3rd@gmail.com).

J Thorac Cardiovasc Surg 2020;160:368-9

$0022-5223 / \$ 36.00$

Copyright (c) 2019 by The American Association for Thoracic Surgery

https://doi.org/10.1016/j.jtcvs.2019.07.060

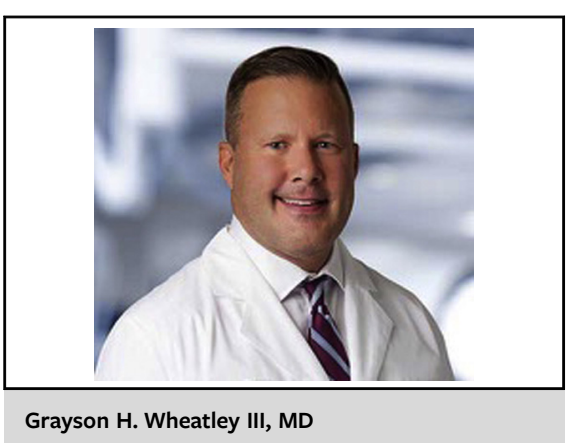

CENTRAL MESSAGE

Aortic tortuosity index is an important predictor of success after thoracic endovascular repair of acute type $\mathrm{B}$ aortic dissections.

thoracic aorta (x-axis) on 3-dimensional reconstructions of computed tomographic angiographic images of the aorta. This angle ranged from $32^{\circ}$ to $85^{\circ}$ in patients in the study of $\mathrm{Li}$ and colleagues, ${ }^{3}$ and a larger $\Phi$ was correlated with an increased degree of aortic tortuosity. The more exaggerated the question mark characteristics of the aorta were, the greater was the aortic tortuosity.

A higher aortic tortuosity index $(\Phi)$ was inversely related to the degree of positive aortic remodeling in patients with acute TBAD after TEVAR. From a flow dynamic perspective, the increased aortic tortuosity increased the sheer and wall stresses associated with blood flow in the aorta, which contributes to the inverse correlation with positive aortic remodeling. With increased sheer and aortic wall stresses resulting from increased aortic tortuosity, the existing TEVAR devices are more challenged to achieve and maintain proximal seal of the endograft against the native aorta. Achievement of a durable proximal seal with TEVAR is essential to the promotion and maintenance of positive remodeling. If proximal seal of the TEVAR device is lost as a result of anatomic factors at the proximal landing zone, such as aortic tortuosity, then antegrade flow into the false lumen could resume and negatively affect thrombosis of the false lumen or transmission of blood pressure in the existing false-lumen thrombus.

We have a great deal more to learn about aortic dissections. With continued study and investigation, all the deep, dark secrets of aortic dissections will ultimately be revealed. At present, though, it is quite valuable to have another upfront data point available to us that can 
help predict which patients with acute TBAD have the best chance of long-term success with TEVAR treatment. The concept of risk stratification of individual patients at the time of presentation-on the basis of both clinical and anatomic characteristics of the aortic dissection-will continue to evolve and to help optimize outcomes of TEVAR for acute TBAD. Calculation of aortic tortuosity index in patients with acute TBAD not only will potentially help in optimal patient selection for TEVAR procedures but could also influence intraoperative treatment strategies. For example, clinicians may choose to modify their intraoperative TEVAR strategy in patients with a high aortic tortuosity index. Additional interventional techniques, such as extension of the length of total aortic coverage with TEVAR, addition of a bare metal stent in the true lumen distal to the TEVAR, or distal landing zone optimization to increase circumferential coaptation of the TEVAR device to the aortic wall, may be pursued in the subset of patients with acute TBAD who have a high aortic tortuosity index. ${ }^{4}$

\section{References}

1. Canaud L, Patterson BO, Peach G, Hinchliffe R, Loftus I, Thompson MM. Systematic review of outcomes of combined proximal stent grafting with distal bare stenting for management of aortic dissection. J Thorac Cardiovasc Surg. 2013;145:1431-8.

2. Sailer AM, Nelemans PJ, Hastie TJ, Chin AS, Huininga M, Chiu P, et al. Prognostic significance of early aortic remodeling in acute uncomplicated type B aortic dissection and intramural hematoma. J Thorac Cardiovasc Surg. 2017;154: 1192-200.

3. Li D, Peng L, Wang Y, Zhao J, Yuan D, Zheng T. Predictor of false lumen thrombosis after thoracic endovascular aortic repair for type B dissection. J Thorac Cardiovasc Surg. 2020;160:360-7.

4. Sharafuddin MJ, Bhama JK, Bashir M, Aboul-Hosn MS, Man JH, Sharp AJ. Distal landing zone optimization before endovascular repair of aortic dissection. J Thorac Cardiovasc Surg. 2019;157:88-98.
See Article page 360.

\section{Commentary: Is it possible to predict the evolution of false lumen in type $B$ aortic dissections treated by thoracic endovascular aortic repair?}

Luca Di Marco, MD, PhD, Alessandro Leone, MD, Luca Botta, MD, Giacomo Murana, MD, PhD, and Davide Pacini, MD, PhD

History teaches us that the possibility of predicting the future has always been a fascinating and at the same time utopian idea for mankind and, in particular, for scientists. In 1555, the French astrologer and physician Michel de Nostredame, familiarly latinized as Nostradamus,

\footnotetext{
From the Cardiac Surgery Unit, Cardio-Thoracic-Vascular Department, S Orsola Hospital, University of Bologna, Bologna, Italy.

Disclosures: Authors have nothing to disclose with regard to commercial support.

Received for publication July 30, 2019; accepted for publication July 30, 2019; available ahead of print Sept 5, 2019.

Address for reprints: Davide Pacini, MD, PhD, Cardiac Surgery Unit, CardioThoracic-Vascular Department, S Orsola Hospital, University of Bologna, Bologna, Italy (E-mail: davide.pacini@unibo.it).

J Thorac Cardiovasc Surg 2020;160:369-70

$0022-5223 / \$ 36.00$

Copyright (c) 2019 by The American Association for Thoracic Surgery

https://doi.org/10.1016/j.jtcvs.2019.07.127
}

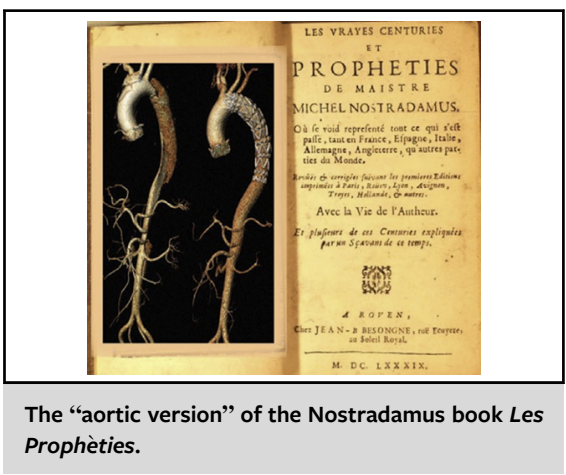

CENTRAL MESSAGE

The degree of the angulation of the aortic arch could be a valid parameter to predict the falselumen thrombosis in type B aortic dissection treated by thoracic endovascular aortic repair.

published the book Les Prophèties, a collection of 942 poetic quatrains allegedly predicting future events. ${ }^{1}$ In the wake of Nostradamus, the seemingly unrealizable idea of foreseeing future events in medicine has never been completely abandoned. In fact, imagine that we have the ability to predict the future. As doctors, we could examine a patient and predict a disease or complication, preventing 